\title{
Coma and spinal cord injury recovery achieved via coordination dynamics therapy
}

\author{
Giselher Schalow* \\ Institute of Exercise Biology and Physiotherapy, Centre of Behavioural and Health Sciences, University of Tartu, Estonia
}

\begin{abstract}
Based on a new development of human neurophysiology, it became possible to partly repair the human brain and spinal cord by a movement-based learning therapy called "coordination dynamics therapy" (CDT). In two short case reports it will be shown that the present medical system is out-of-date by 30 years. That a spinal cord injury patient can re-learn walking and gets the urinary bladder functions repaired, which is the biggest problem in spinal cord injury, seems for the expensive conventional rehabilitation out-of-scope. In the second case report it is shown that patient being in the permanent coma, could be brought out-of-coma via CDT six years after the accident. If it is not tried by efficient treatment to get long-term coma patients out of the coma, means modern euthanasia. That brain repair is even partly possible in extreme brain injury is due to the development of human neurophysiology and especially the electrophysiology and not due to animal research; only $0.3 \%$ of the data have consequences for human patients.
\end{abstract}

\section{Introduction}

It has been published that CDT can improve or repair central nervous system (CNS) functioning after stroke [1], traumatic brain injury [2,3], spinal cord injury [4-7], cerebellar injury [8], cerebral palsy [9], hypoxic brain injury [10], in Parkinson's disease [11,12], spina bifida (myelomeningocele) [13] and scoliosis [14]. Speech had been induced and improved in a patient with severe cerebral palsy [15] and urinary bladder functions were repaired in patients with spinal cord injury $[7,15]$. In patients with cancer, especially breast cancer, cancer growth inhibition could be achieved via CDT [16]. A partial repair of the brain in a coma patient who lost approximately $50 \%$ of the brain is given below. Also, brain damage due to high pressure waves caused by an explosion or bullet should be treatable. Details of human neurophysiology and movement-based learning for repairing the neural networks of the human CNS have been published in three books $[15,17,18]$ and an extended abstract [19]. A very short introduction is given below to make the level of development of the process of developing coordination dynamics therapy understandable.

An important question of brain repair following traumatic brain injury is, with how much lost brain tissue a patient can recover from coma and may get a meaningful life back. As reported here, even a patient with approximately $50 \%$ lost brain tissue could recover from coma when CDT was administered aggressively for 5 years. The beginning of the therapy of the coma patient was giving in detail in [20]. Interesting and important for the society and the family is how far can the patient be brought. The extent of damage to the connections between different cortical areas or brain parts (disconnection syndrome) is another important factor for repair, even though difficult to evaluate.

\section{Method}

\section{Coordination Dynamics Therapy (CDT)}

Based on the analysis of the nerve fiber composition of the human lower sacral nerve roots, a recording method was developed, with which it is possible to record simultaneously with two pairs of wire electrodes from several single-afferent and efferent nerve fibers under nearly natural conditions [21]. Figure 1 shows the human Central Nervous System (CNS), the spinal canal with the cauda equina nerve roots and the recording condition during an operation.

Removing the nerve roots after recording and performing morphometry, a classification scheme of peripheral nerve fibers of the human nervous system could be developed (Figure 2), in which a nerve fiber group is characterized by a group conduction velocity and a group nerve fiber diameter [22].

By being able to record simultaneously now from identified singleafferent and efferent nerve fibers, it becomes possible to analyze the self-organization [23] of the neuronal networks at the single-neuron level of the human CNS under physiologic and pathophysiologic conditions. The single-nerve fiber firing can be correlated to singlemotor unit firing by surface electromyography $[15,17,18]$.

The most important finding is that human neuronal networks organize themselves by phase and frequency coordination [24] of single-neurons (Figure 3), subnetworks (network oscillators) and networks. The rhythmic firing of the spinal oscillators helps to identify firing patterns and to repair injured networks by a coordinated rhythm training (Figure 4).

When exercising on a special CDT device (Figure 4), coordinated arm and leg movements are performed and trained. This special CDT device has three advantages. First, coordinated arm, leg and trunk movements are performed. Second, the device is made very exact, so

Correspondence to: Giselher Schalow, Institute of Exercise Biology and Physiotherapy, Centre of Behavioural and Health Sciences, University of Tartu, 5 Jakobi Street, Tartu 51014, Estonia, E-mail: g_schalow@hotmail.com

Received: December 27, 2017; Accepted: January 16, 2018; Published: January 19,2018 


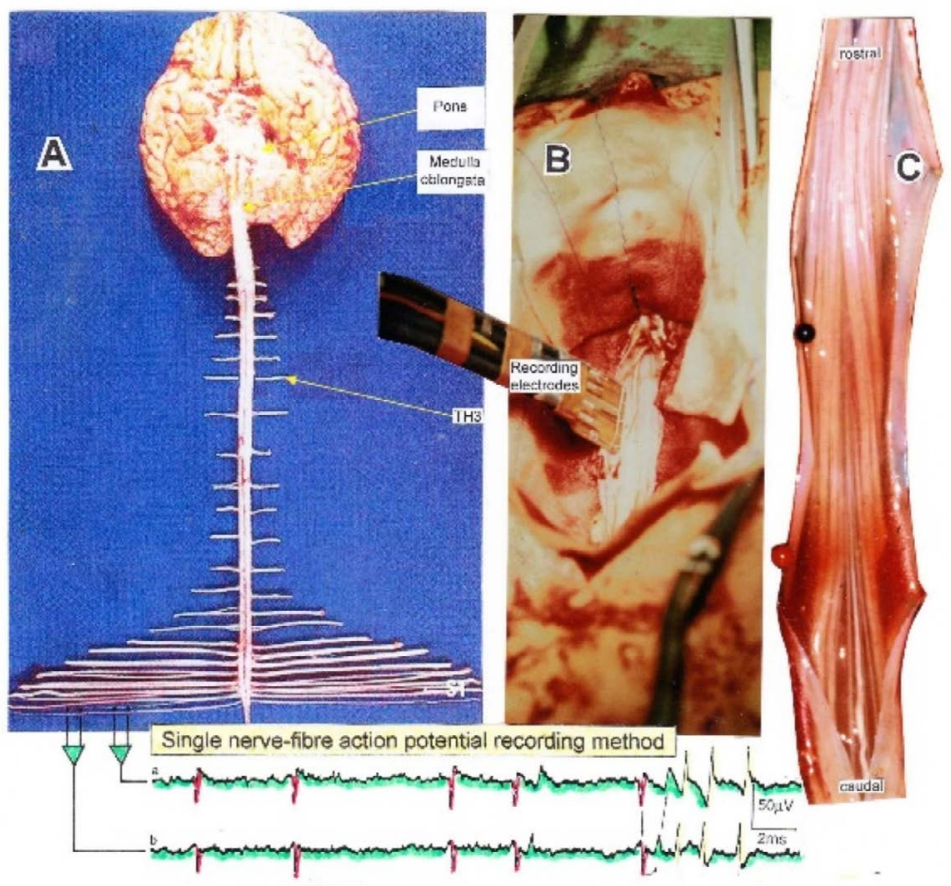

Figure 1. Layout of the recording of single-nerve fiber action potentials to analyze the self-organization of neuronal networks of the human CNS under physiologic and pathophysiologic conditions. By recording with two pairs of platinum wire electrodes (B) from sacral nerve roots (cauda equina, C) containing between 200 and 500 myelinated nerve fibers, records were obtained in which single nerve-fiber action potentials (APs) were identified from motoneurons (main AP phase downwards) and afferents (main AP phase upwards). By measuring the conduction times and with the known electrode pair distance $(10 \mathrm{~mm})$, conduction velocity distribution histograms were constructed in which the myelinated nerve fiber groups larger than $4 \mu \mathrm{m}$ could be characterized by group conduction velocity values. After the recording, morphometry was performed. Distributions of nerve fiber diameters were constructed and nerve fiber groups were characterized by the peak values of asymmetrical distributions. By correlating the peak values of the velocity distributions with those of the diameter distributions obtained for the same root, a classification scheme was constructed of the human peripheral nervous system. It became thus possible to record natural impulse patterns simultaneously from identified single afferent and efferent nerve fibers and to analyze self-organizing mechanisms of the human CNS under physiologic and pathologic conditions.

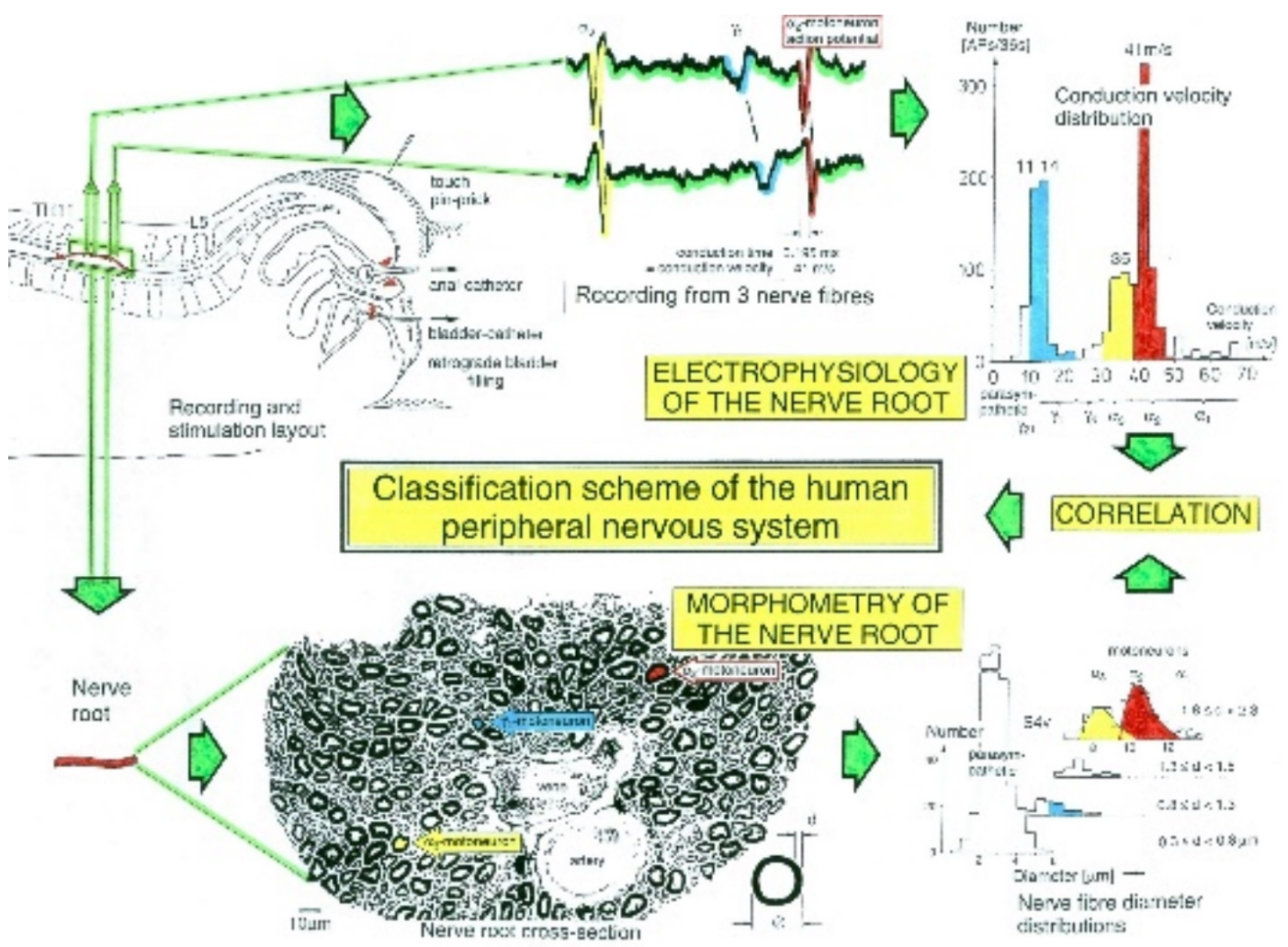

Figure 2. Development of a classification scheme for human peripheral nerve fibers. Conduction velocities (V) and nerve fiber diameters $(\varnothing)$ of afferent and efferent nerve fiber groups in normal humans and in patients with a traumatic spinal cord injury for 0.5 to 6 years. 


\section{Relative phase and frequency coordination of the oscillatory firing $\alpha_{2}$-motoneuron $\mathrm{O} 2$ and the firing of the secondary muscle spindle afferent fibre SP2(1)}
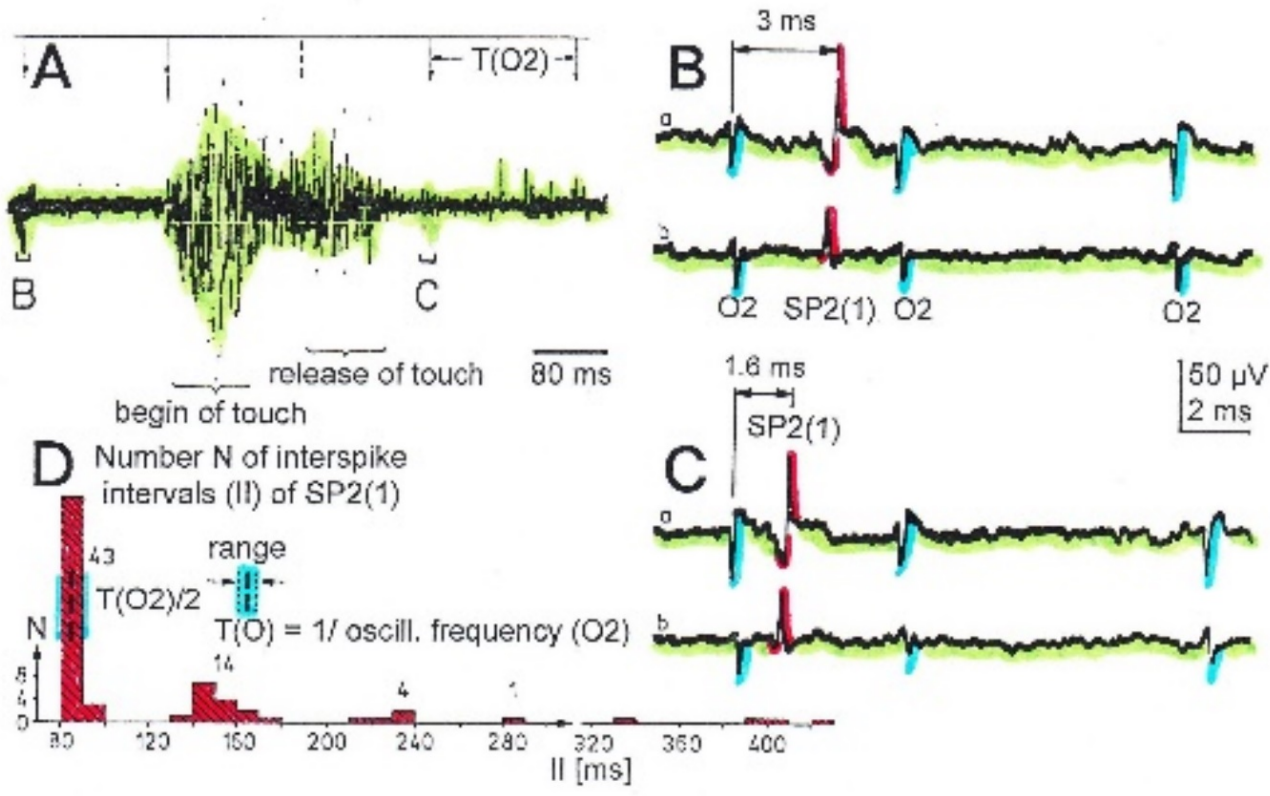

Figure 3. Time relation between the occurrence of the action potentials (APs) of oscillatory firing $\alpha 2$ - motoneuron $\mathrm{O} 2$ and the firing of the secondary muscle spindle afferent fiber SP2(1) Brain-dead human HT6. S4 dorsal root recording. A. Overall view of the used sweep piece; only trace "a" shown. Four oscillation cycle periods of motoneuron $\mathrm{O} 2$ are indicated $(\mathrm{T}(\mathrm{O} 2))$ The APs of the impulse trains can be recognized only partly, because of the slow time base and poor digitalization. One impulse train (dashed arrow) is lost in the touch stimulated activity, which consists of a touch (large overall activity) and a release part (lower overall amplitude). B,C. Sweep pieces from A, time stretched. In B, motoneuron impulse train APs is marked O2, spindle afferent APs are marked SP2(1). Note that the APs of the spindle afferent fiber are not time-locked to the first AP of the impulse train of the rhythmically firing motoneuron (relative phase coordination). Digitalization 4 times better than in A, but still rather poor, as can be seen from the low amplitudes of the motoneuron APs on trace "b" in C. D. Occurrence of interspike intervals of the secondary muscle spindle afferent fiber SP2(1). The numbers give the amount of IIs in each distribution peak. The oscillation period of motoneuron O2 (and the range of variation) and the half period are indicated by short dashed lines. Note that the IIs of fiber SP2(1) are very similar to the oscillation period (or the half of it) of a

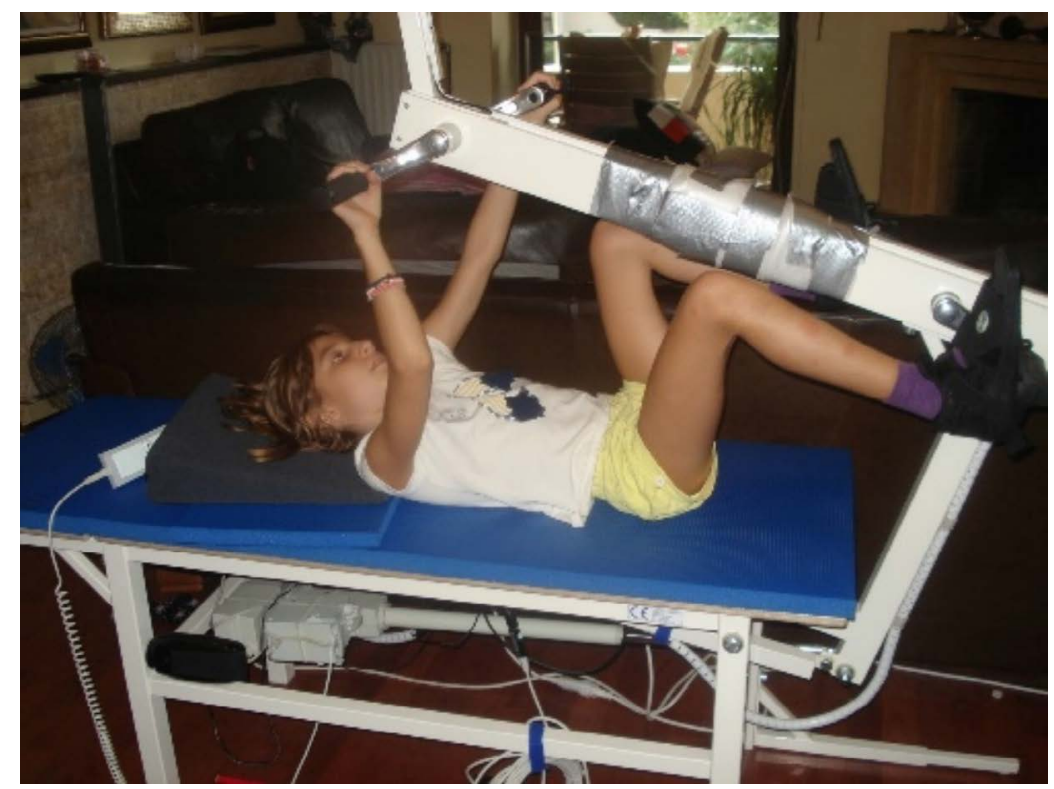

Figure 4. The 10-year-old Nefeli with an incomplete spinal cord injury is exercising coordinated arm, leg and trunk movements to improve the coordinated firing neurons and sub neuronal networks. This special CDT device for measuring and therapy (int.pat.) is produced by the firm: Giger Engineering, Martin Giger dipl.Ing.ETH/SIA, Herrenweg 1, 4500 Solothurn, Switzerland, www.g-medicals.ch. 
that the nervous system can learn from the movement-induced afferent input for neural network repair. Third, since the coordination between arms and legs changes from pace gait to trot gait and backwards, very difficult and coordinated arm and leg patters are performed during exercising, which train the neural networks deeply in the complexity of CNS organization.

Such pattern changes from pace to trot gait allows a measurement of CNS functioning [23] by the so-called coordination dynamics values. The progress of CNS repair can therefore non-invasively measured with ongoing therapy by a single value.

The goal of coordination dynamics therapy (CDT) is firstly to improve the by the injury, malformation or degeneration impaired phase and frequency coordination by exercising on the special CDT device (Figure 4). Secondly, by exercising movement automatisms like creeping, crawling, walking and running, if possible, healthy parts of the brain can take functions over from the injured ones. Also, oldlearned movements are helpful for enhancing the plasticity. The, to a very limited extent, newly build neurons [25], caused by movementbased learning, will contribute to the repair.

The power of CDT is now demonstrated on a patient with a spinal cord injury and a patient being in permanent coma.

\section{Results}

\section{Case report 1}

The five-year-old Nefeli became cancer. When the cancer was removed she suffered a spinal cord injury at the levels Th10/11 by a mistake of the surgeon. Being in the wheelchair (Figure 5A), eight months of conventional physiotherapy were administered to her with little progress. She had difficulties to manage at school (Figure 5B). Later on, Nefeli refused further conventional physiotherapy, mainly because no further progress was achieved.

In spinal cord injury, in the first 6 to 12 months the injured CNS mainly repairs itself, which is often 'sold' as successful rehabilitation. One year after the accident further repair can only be achieved with an efficient repair treatment.

At an age of nine the spinal cord injury patient started the movement-based learning method CDT. Within two years of CDT, Nefeli learned to walk and her urinary bladder $[7,15]$ and bowel functions were partly repaired by learning transfer [26]. She could manage now much better at school. She could also walk to the whiteboard and write there (Figure 6).

In the now 12-years old Nefeli still the walking and the urinary bladder functioning have to be improved. Also, the scoliosis [14] has to be improved and can be improved by exercising rotational trunk movements on the special CDT device. Nefeli can partly control the bladder, but the filling volume has to be increased from around $80 \mathrm{ml}$ to $200 \mathrm{ml}$. Also, the time from the first wish to void to the urgency to void has to be increased. Now the time is with approximately $20 \mathrm{~min}$ too short. No bowel pain occurs any more. But the 'wind' is not fully under control. The running and jumping, which the spinal cord injury girl Nefeli likes very much, has to be further improved.

\section{Case report 2}

The 22-year-old man Manolis suffered in a car accident an extreme severe brain injury. In the accident a metal shard went into his right brain and nervous tissue was lost. The severances of the injury can partly be seen in Figure 7. After surgery in a university clinic he was send to a
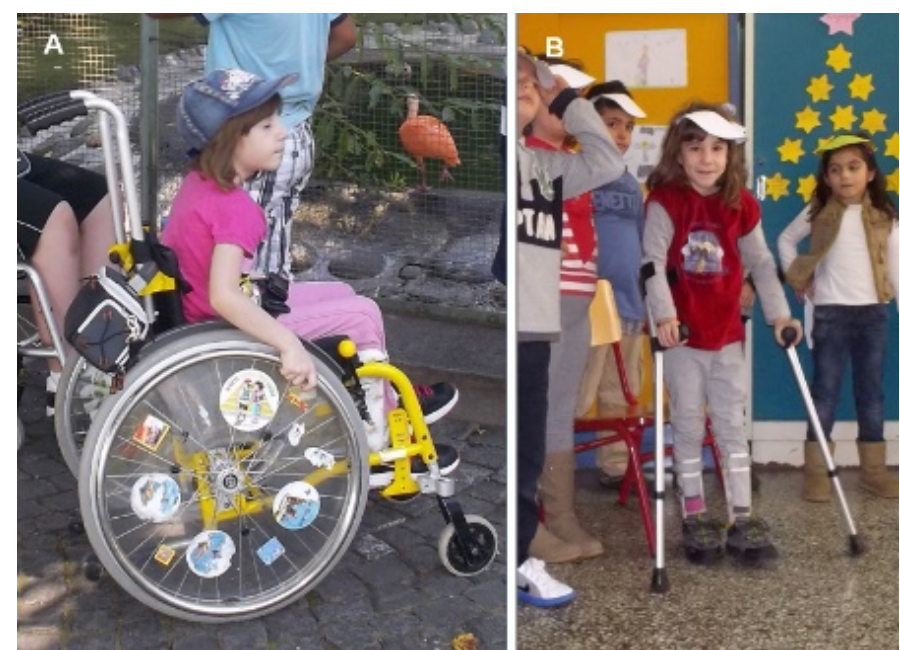

Figure 5. The six-year-old patient Nefeli with a spinal cord injury at the levels Th10/11 in the wheel chair (A) and with orthoses and sticks at school (B) after obtaining conventional physiotherapy.
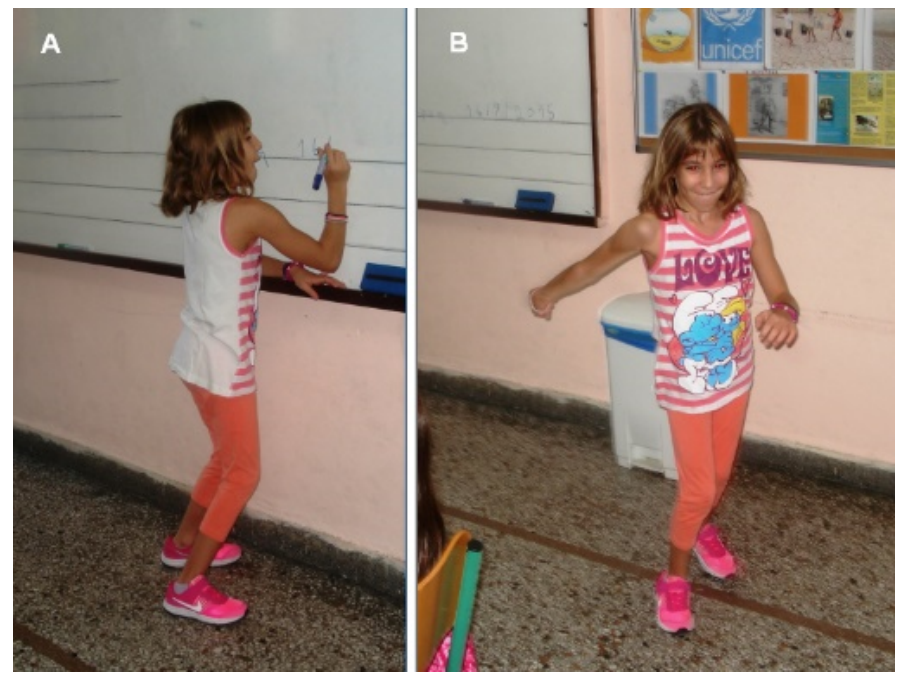

Figure 6. The now 11-year-old patient Nefeli with a spinal cord injury at the levels Th10/11 partly re-learned to walk and is able to go to the white-board at school and write. Note, at the whiteboard, she had support herself a bit for writing (A).

conventional rehabilitation center. At the beginning of rehabilitation, the relations could communicate with the patient by eye blinking. After a few months this communication was lost. The pathologic processes seemed to have won against the physiologic ones. The family did not want that Manolis would die, so they took him out of the rehabilitation center and started CDT with a lot of vegetative nervous system problems at the beginning as for example the blood pressure.

It has been published that also coma patients can be treated with CDT [18]. Figure 8 shows how the coma patient Manolis was passively trained. Realizing the tremendous damage of the brain of Manolis (Figure 7), the Author himself has doubts whether it would be possible to get him out-of-coma.

After three years of CDT, the permanent coma patient slowly reached the minimally consciousness state [27]. After five years of CDT, six years after the accident, Manolis was fully out-of-coma. He now can play and laugh with the mother (Figure 10) and can sit freely (Figure 11). He can generate sounds, but he cannot speak till now. The left hemisphere, where the main speech centers are, is not damaged so 

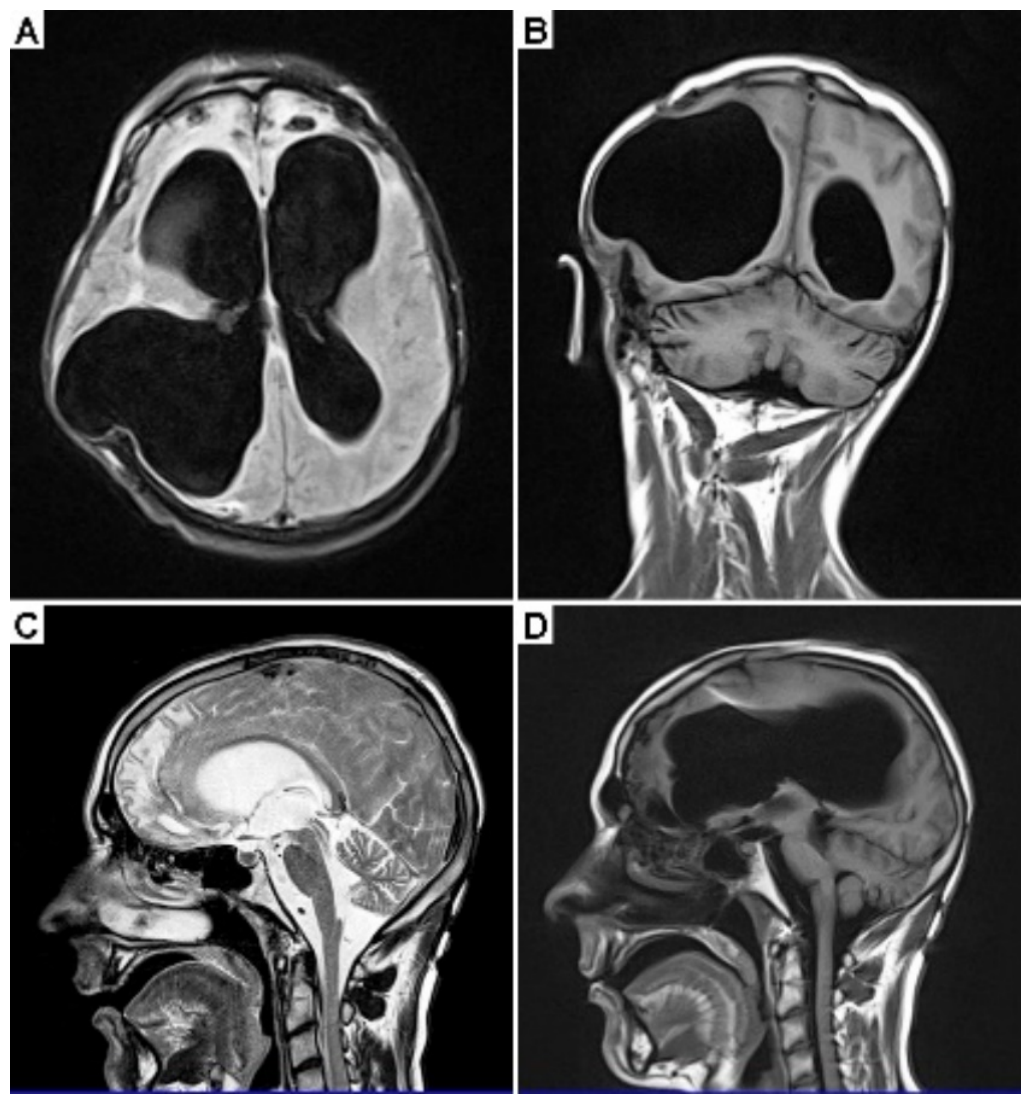

Figure 7. MRI of a 22-year-old male patient with a very severe traumatic brain injury. The pictures were taken one year after the car accident. Since a metal shard went into the brain during the accident, some brain tissue had to be removed. A shunt was installed to regulate brain pressure. Because of the loss of nervous tissue, the ventricles became enlarged; they look like in cases of hydrocephalus. Many parts of the brain were damaged during the accident. Both frontal lobes were damaged (A, C). The artifact from the shunt can be seen in ' $\mathrm{C}$ '.
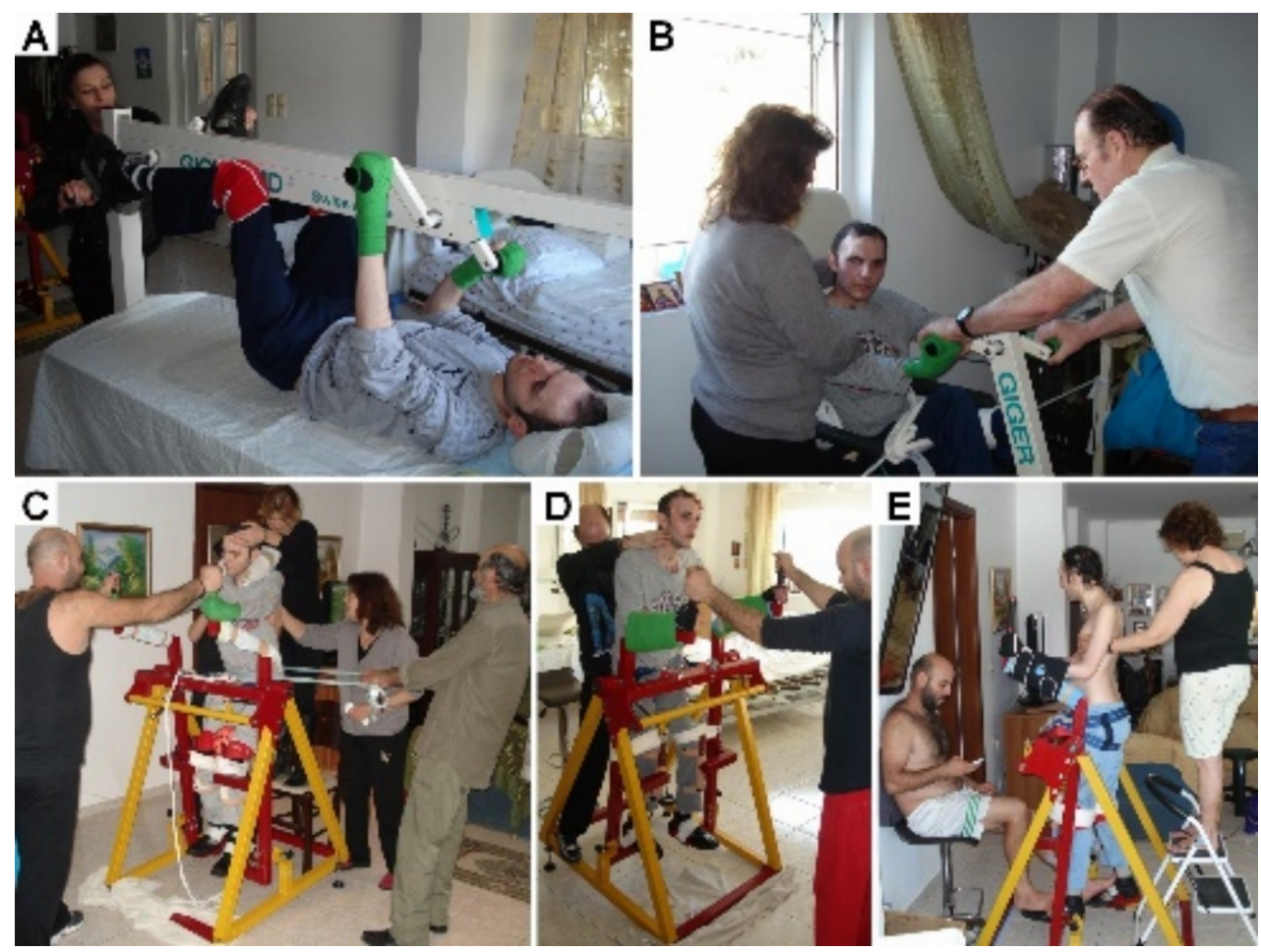

Figure 8. Movements performed with a 23-year-old male patient in the vigilant coma by the family members. All movements were passively performed, because the patient was in a coma. A,B. Exercising on the special CDT device in the lying position (both hands are fixed) and sitting position. C,D,E. Exercising on the Sky-walker. Note that the trunk and head control improved from 'C' to 'E'; in 'E' no support of the head was needed any more after 5 months of CDT. 
much. It could therefore be that the patient also re-learns a bit to speak. After being out of the coma and being able to move a bit on volition the head, trunk and right arm, it seems that the speed of repair of the former coma patient increased. But there are a lot of spasticity problems and whether he can reach the meaningful life state is still unclear. There is no experience with the treatment results of such severe brain injury patients. When the Author saw the first time that the patient could lift his head and kiss the mother after four years of CDT, he had the feeling that the patient raised from the dead.

The improvement of CNS functioning can also be seen in the expression of the face. In Figure 9 the face of the patient is shows when being in the coma. But when being able to play with the mother again, there is life in his face again (Figure 10).

After five years of CDT, six years after the accident, the patient can keep the crawling position. Its variation has to be trained in the future.

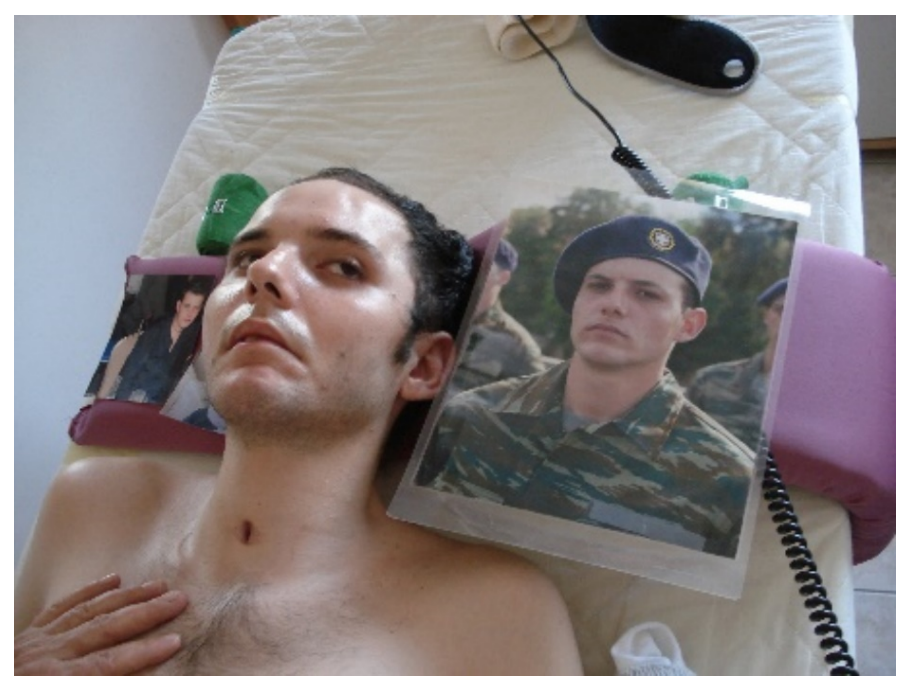

Figure 9. Picture of the 23-year-old patient being 1.5 years in the vigilant coma following a car accident. The impression in his face does not look as healthy as the one of the picture made 2 years before when he was in the army.

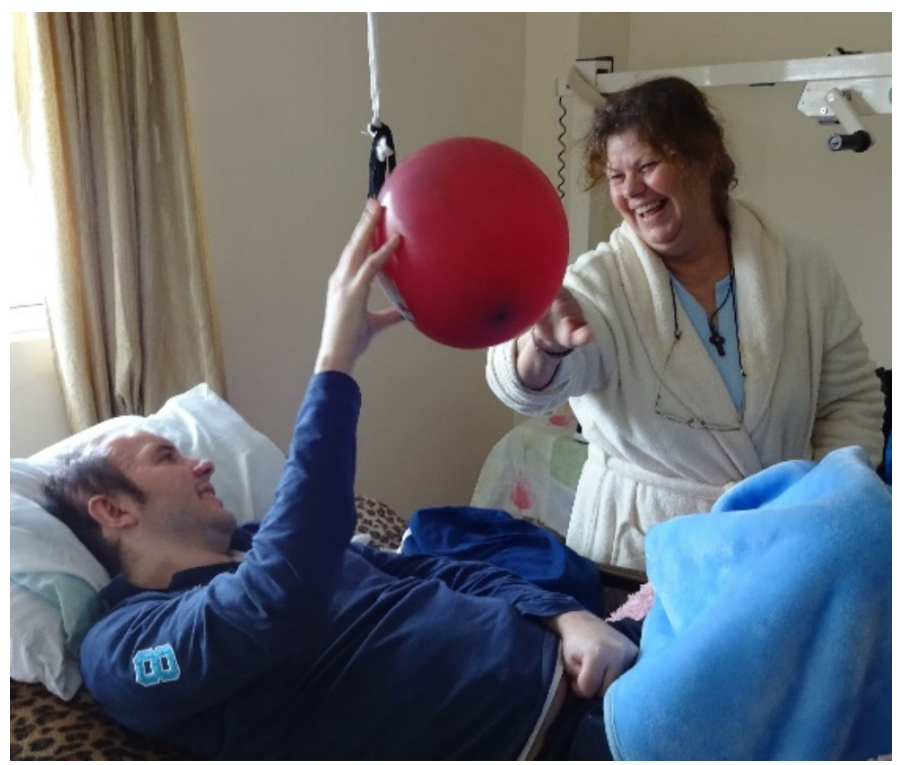

Figure 10. The mother of a former coma patient is playing with the son to catch the balloon. The movement angles of the patient's right arm are limited. The left hand is a spastic state. Both enjoy the game.

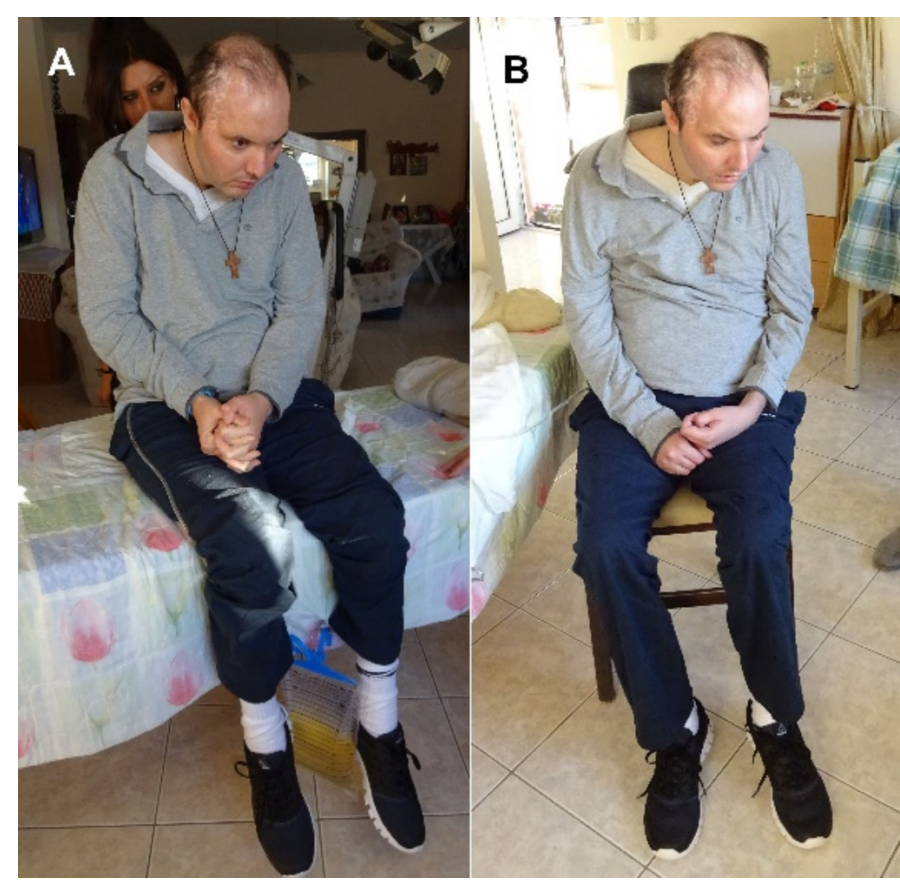

Figure 11. The patient Manolis with an extreme brain injury after recovering from coma. He can freely sit on the bed (A) and on a chair (B). Note the relative good face expression in A. He seems to concentrate to be able to sit freely.

He can also sit freely (Figure 11), but he cannot stand. For further details of the problems at the beginning of therapy see [20].

\section{Conclusion}

It was shown that based on a new development in human neurophysiology the human nervous system could partly be repaired by a new treatment, called coordination dynamics therapy, in a patient with a spinal cord injury and a patient with an extremely injured brain. There are important consequences for the society to be done.

First, human neurophysiology has to be red at medical schools or universities, so that physiotherapists and physicians have the knowledge to understand human brain repair, because CNS repair is different in animals and humans. In animals mainly the nerve fiber growing strategy is used, whereas in humans movement-based learning is used. Only $0.3 \%$ of the data have consequences for human patients [28].

Second, at least in some cases it is possible to get permanent coma patients out of coma, which would otherwise stay permanently in coma or die. Not to offer such coma patients efficient neuro-therapy means contributing to modern euthanasia.

The Author is a private researcher in human neurophysiology and clinical research and is living and performing research on 1200 Euro. For the upper research project, it is not possible to get funding, even though the Author was post doc with Sir Bernard Katz, Huxley and Ricardo Miledi, Department of Biophysics, University Collage London.

\section{References}

1. Schalow G (2002) Stroke recovery induced by coordination dynamic therapy and quantified by the coordination dynamic recording method. Electromyogr Clin Neurophysiol 42: 85-104. [Crossref]

2. Schalow G (2002) Improvement after traumatic brain injury achieved by coordination dynamic therapy. Electromyogr Clin Neurophysiol 42: 195-203. [Crossref] 
3. Schalow, G, Jaigma P (2006) Improvement in severe traumatic brain injury induced by coordination dynamics therapy in comparison to physiologic CNS development. Electromyogr Clin Neurophysiol 46: 195-209. [Crossref]

4. Schalow G (2002) Recovery from spinal cord injury achieved by 3 months of coordination dynamic therapy. Electromyogr Clin Neurophysiol 42: 367-376. [Crossref]

5. Schalow G (2003) Partial cure of spinal cord injury achieved by 6 to 13 months of coordination dynamic therapy. Electromyogr Clin Neurophysiol 43: 281-292. [Crossref]

6. Schalow G, Jaigma P, Belle VK (2009) Near-total functional recovery achieved in partial spinal cord injury ( $50 \%$ injury) after 3 years of coordination dynamics therapy. Electromyogr Clin Neurophysiol 49: 67-91. [Crossref]

7. Schalow G (2010) Cure of urinary bladder functions in severe (95\%) motoric complete cervical spinal cord injury in human. Electromyogr Clin Neurophysiol 50: 155-179. [Crossref]

8. Schalow G (2006) Cerebellar injury improvement achieved by coordination dynamics therapy. Electromyogr Clin Neurophysiol 46: 433-439.

9. Schalow G, Jaigma P (2005) Cerebral palsy improvement achieved by coordination dynamics therapy. Electromyogr Clin Neurophysiol 45: 433-445. [Crossref]

10. Schalow G (2006) Hypoxic brain injury improvement induced by coordination dynamics therapy in comparison to CNS development. Electromyogr Clin Neurophysiol 46: 171-183. [Crossref]

11. Schalow G, Pääsuke M, Ereline J, Gapeyeva H (2004) Improvement in Parkinson's disease patients achieved by coordination dynamics therapy. Electromyogr Clin Neurophysiol 44: 67-73. [Crossref]

12. Schalow G (2015) Human neurophysiology and movement-based learning for repairing the human brain. In: "Horizons in neuroscience research. Volume22". Editors: Andreas Costa and Eugenio Villalba. Nova Science Publishers, Inc., Hauppauge NY, USA, 31-137.

13. Schalow G, Nyffeler T (2001) Koordinationsdynamik-Therapie: Myelomeningozele (Spina bifida). Physiotherapie.

14. Schalow G, Nyffeler T (2000) Koordinatiosdynamik-Therapie: Skoliose. Physiotherapy.

15. Schalow G (2013) Human Neurophysiology: Development and Repair of the Human Central Nervous System. Nova Science Publisher, Hauppauge NY, USA.

16. Schalow G (2017) Breast cancer grows inhibition via coordination dynamics therapy. In: "Horizons in Cancer Research", Volume 68. Nova Science Publisher, New York.
17. Schalow G (2015) Repair of the Human Brain and Spinal Cord. Nova Science Publisher, Hauppauge NY, USA.

18. Schalow G (2015) Neural network learning in humans. Nova Science Publishers, Inc., Hauppauge NY, USA, 329.

19. Schalow G (2015) Human neurophysiology and movement-based learning for repairing the human brain. In: "Horizons in neuroscience research. Volume22". Editors: Andreas Costa and Eugenio Villalba. Nova Science Publishers, Inc., Hauppauge NY, USA, $31-$ 137.

20. Schalow G (2017) Coma recovery achieved after 4 years of coordination dynamics therapy of a patient who lost $50 \%$ of his brain tissue in a car accident. In: "Horizons in Neuroscience Research”. Volume 32. Nova Science Publisher, New York.

21. Schalow G, Lang G (1987) Recording of Single Unit Potentials in Human Spinal Nerve Roots: a New Diagnostic Tool. Acta Neurochir. 86: 25-29.

22. Schalow G, Zäch GA, Warzock R (1995) Classification of human peripheral nerve fibre groups by conduction velocity and nerve fibre diameter is preserved following spinal cord lesion. J Auton Nerv Syst 52: 125-150. [Crossref]

23. Kelso JAS (1995) Dynamic Patterns. The Self-Organization of Brain and Behavior. MIT Press, Cambridge.

24. Schalow G (2005) Phase and frequency coordination between neuron firing as an integrative mechanism of human CNS self-organization. Electromyogr Clin Neurophysiol 45: 369-383. [Crossref]

25. Schalow G (2009) Building of New Motoneurons in the Human Spinal Cord upon Coordination Dynamics Therapy to Improve Finger Functions in Motoric Complete Cervical Spinal Cord Injury. In: Berkovsky TC (Ed.), Handbook of Spinal Cord Injuries, Chapter 4. 231-264, Nova Science Publishers.

26. Schalow G (2010) Scientific basis for learning transfer from movements to urinary bladder functions for bladder repair in patients with spinal cord injury. Electromyogr Clin Neurophysiol 50: 339-395. [Crossref]

27. Schnakers C, Vanhaudenhuyse A, Giacino J, Ventura M, Boly M, et al. (2009) Diagnostic accuracy of the vegetative and minimally conscious state: clinical consensus versus standardized neurobehavioral assessment. BMC Neurol 9: 35. [Crossref]

28. (in TV (3sat, nano, Dr.rer.nat Toni Lindl, 2015).

Copyright: $\odot 2018$ Schalow G. This is an open-access article distributed under the terms of the Creative Commons Attribution License, which permits unrestricted use, distribution, and reproduction in any medium, provided the original author and source are credited. 